\title{
Ambulatory Holter monitoring in asymptomatic patients with DDD pacemakers - do we need ACC/AHA Guidelines revision?
}

Michal Chudzik, Artur Klimczak, Jerzy Krzysztof Wranicz

Department of Electrocardiology, Medical University of Lodz, Poland

Submitted: 6 March 2011

Accepted: 19 June 2011

Arch Med Sci 2013; 9, 5: 815-820

DOI: 10.5114/aoms.2013.38675

Copyright @ 2013 Termedia \& Banach

\author{
Corresponding author: \\ Michal Chudzik MD \\ Department \\ of Electrocardiology \\ Medical University of Lodz \\ 1/3 Sterlinga St \\ 91-425 Lodz, Poland \\ Phone: +48 691941814 \\ E-mail: michalchudzik@wp.pl
}

\begin{abstract}
Introduction: We sought to determine the usefulness of ambulatory 24-hour Holter monitoring in detecting asymptomatic pacemaker (PM) malfunction episodes in patients with dual-chamber pacemakers whose pacing and sensing parameters were proper, as seen in routine post-implantation follow-ups. Material and methods: Ambulatory 24-hour Holter recordings (HM) were performed in 100 patients with DDD pacemakers 1 day after the implantation. Only asymptomatic patients with proper pacing and sensing parameters (assessed on PM telemetry on the first day post-implantation) were enrolled in the study. The following parameters were assessed: failure to pace, failure to sense (both oversensing and undersensing episodes) as well as the percentage of all PM disturbances.

Results: Despite proper sensing and pacing parameters, HM revealed PM disturbances in 23 patients out of 100 (23\%). Atrial undersensing episodes were found in 12 patients $(p<0.005)$ with totally 963 episodes and failure to capture in 1 patient (1\%). T wave oversensing was the most common ventricular channel disorder (1316 episodes in 9 patients, $p<0.0005$ ). Malfunction episodes occurred sporadically, leading to pauses of up to $1.6 \mathrm{~s}$ or temporary bradycardia, which were, nevertheless, not accompanied by clinical symptoms. No ventricular pacing disturbances were found.

Conclusions: Asymptomatic pacemaker dysfunction may be observed in nearly $25 \%$ of patients with proper DDD parameters after implantation. Thus, ambulatory HM during the early post-implantation period may be a useful tool to detect the need to reprogram PM parameters.
\end{abstract}

Key words: DDD pacemaker, ambulatory Holter monitoring, pacemaker dysfunction.

\section{Introduction}

According to ACC/AHA [1] guidelines 24-hour ECG Holter monitoring (HM) in asymptomatic patients in the early period after pacemaker (PM) implantation is not recommended (class $\mathrm{llb}$ ). Holter monitoring is an alternative method for telemonitoring of patients with PMs. Modern PMs and endocardial leads compared to the first ones are really perfect devices, with low frequency of dysfunctions [2-7]. On the other hand, since the first implantation of a permanent pacing system in 1958, progressive technology development has led to extremely complex dual chamber devices, with many therapeutic and diagnostic algorithms [1-5].

Data about HM in patients with DDD PMs are limited. Despite proper PM parameters, asymptomatic episodes of sensing and pacing malfunc- 
tion might occur even immediately after the implantation. Marked development of PMs and lead technology in the last years did not completely eliminate the risk of electrode dislodgment. Additionally, sophisticated complex algorithms of modern PMs do not eliminate, but may even increase the risk of PM dysfunction. Usually, after PM implantation the majority of factory parameters are not reprogrammed. Routine short-term PM follow-up and 12-lead ECG are not able to change these settings. Maybe HM will be useful to confirm correct PM pacing and sensing parameters and ideal pacemaker functioning during the whole day of each patient's daily activity.

However, more sophisticated PM systems are often associated with increased costs, frequent complications and the need for more complex follow-up procedures. Proper parameter programming after implantation should be a routine procedure for every patient. Unfortunately, PM telemetry only provides us with data about a short period of device examination. Additionally, this follow-up procedure is performed in patients at rest. Long-term assessment of PM function may be performed by applying 24-hour ambulatory Holter monitoring (HM). This method was introduced as a PM evaluation strategy in the 1970s [6, 7]. Thus far, HM has been mainly used to detect dysfunction in single-chamber PMs.

We sought to determine the usefulness of ambulatory HM in detecting asymptomatic PM malfunction episodes in the early, dual-chamber pacemaker post-implantation period, in patients whose pacing and sensing parameters were proper, as seen in routine post-implantation follow-ups.

\section{Material and methods}

\section{Study population}

One hundred and two patients with dual-chamber Biotronik Talos DR PMs, implanted between 2009 and 2010, were initially included in this prospective study. Two patients were excluded from the study due to a ventricular pacing threshold $>1 \mathrm{~V}$, although these values are within the acceptable $(1.2 \mathrm{~V}$ and $1.3 \mathrm{~V})$ range. Therefore, the final study population consisted of 100 patients who presented proper pacing and sensing parameters, which were assessed the day after the implantation (see below for accepted "normal values"). In all these patients, $\mathrm{HM}$ recordings were performed the day after the implantation (early post-implantation period).

\section{Implantation procedure}

All implantations were performed by two experienced cardiologists. Active fixation leads to the right atrium appendage and to the right ventricular outflow tract (RVOT) were implanted in all cas- es. All leads were inserted by blind subclavian or axillary vein puncture. Fluoroscopy and intracardiac electrogram (IEGM) confirmed the proper positioning of the leads. The following electrical parameters were considered normal: atrial pacing threshold $<1 \mathrm{~V}$, ventricular pacing threshold $<0.5 \mathrm{~V}$ with a width of $0.5 \mathrm{~ms}$. For sensing, the acceptable values were: stable atrial $P$ wave $>2 \mathrm{mV}$, and ventricular R wave amplitude $>8 \mathrm{mV}$. Then, the leads were connected to the pacemaker.

\section{Pacemaker parameters}

The day after the implantation, all PM parameters were analyzed with the Biotronik ICS 3000 programmer. Patients with the following parameters were included in the study: atrial pacing threshold $<1.5 \mathrm{~V}$, ventricular pacing threshold $<1 \mathrm{~V}$ with a width of $0.4 \mathrm{~ms}$. For sensing: stable atrial $P$ wave $>2 \mathrm{mV}$, and ventricular $\mathrm{R}$ wave amplitude $>8 \mathrm{mV}$. Pacing in unipolar and sensing in bipolar configuration were measured in each patient. The following PM parameters were programmed: basic rate60 or 70 bpm, upper rate -120 bpm; unipolar pacing amplitude $-3.6 \mathrm{~V}$ with a width of 0.4 for both channels; atrial bipolar sensing $-0.5 \mathrm{mV}$, ventricular bipolar sensing $-2.5 \mathrm{mV}$, atrial refractory period $-450 \mathrm{~ms}$, ventricular refractory period - $250 \mathrm{~ms}$, AV delay fixed - $180 \mathrm{~ms}$. Proper sensing function was assessed through IEGM from atrial and ventricular leads. Additionally, retrograde conduction was tested in VDI mode at $100 \mathrm{bpm}$. No PM disturbances were observed in standard 12-lead ECG performed in all study participants. Post-implantation radiography was also performed in all cases.

\section{Holter monitoring}

In all patients, HM was performed the day after the implantation to evaluate oversensing and undersensing episodes as well as stimulation disturbances. All Holter recordings were started after the parameters were analyzed with the PM programmer. Recordings were performed using analog Oxford MR 45 recorders (typical CM5, CM2 canals) and tapes were next analyzed by means of the Oxford Medilog Excel 2 System according to ACC/AHA guidelines [8]. The analysis was performed both automatically and manually using a special PM analysis program. The manual analysis included the hourly editing and evaluation of minimal and maximum heart rate as well as the analysis of all pauses during the programmed basic pacing rate. Except for tabular analysis and histograms, all data were evaluated in full disclosure format.

Failure to pace (FP), and failure to sense (FS) were evaluated. Failure to pace episodes were divided into oversensing (FSO) and undersensing (FSU) 
episodes. Failure to pace was described as the lack of effective stimulation after a PM spike, while undersensing was considered an inappropriate PM spike and oversensing an excessively long interval between paced spikes (longer than the basic pacemaker rate). Cross-sensing was evaluated as well as pacemaker mediated tachycardia (PMT). The percentage of all PM disorders (including FS, FP as well as cross-sensing and PMT) was also assessed in patients with sinus rhythm.

In every patient with PM disturbances found in $\mathrm{HM}$, pacemaker parameters were corrected and for the next $24 \mathrm{~h}$, HM was performed.

\section{Statistical analysis}

Statistical analysis was performed using the Statistica program. All continuous data were presented as mean \pm SD. Dichotomous variables were presented as counts and proportions, continuous variables as medians, minimum and maximum. For comparison of dichotomous variables, Fisher's exact test was used. Continuous variables were compared using the Wilcoxon test because of unknown distribution (non-normal distribution). A probability of less than 0.05 was considered statistically significant. All significance tests were two-tailed.

\section{Results}

The final study population consisted of 100 asymptomatic patients, 58 male, 42 female, $52-78$ years old (average: $67 \pm 7$ ), with DDD Biotronik Talos DR pacemakers, and Setrox S. Table I lists the clinical characteristics of the participating patients. The PM parameters, which were gathered by the ICS 3000 programmer on the day after the implantation, are shown in Table II. No signs of improper PM function were observed during the routine PM followup. Radiography performed after the implantation did not reveal any lead dislodgment.

Table III summarizes the pacemaker dysfunctions found via ambulatory Holter monitoring. Despite proper parameters during the standard programming follow-up, $23 \%$ of the patients displayed pacemaker dysfunction episodes during Holter monitoring on the same day. Although proper $\mathrm{P}$ wave amplitude and bipolar sensing configuration were displayed, during the routine follow-up, HM revealed atrial undersensing episodes in 12 patients; additionally, one patient presented episodes of atrial failure to capture. The number of atrial FSU episodes ranged from 5 to 700 (mean 79, median 16), which corresponds to $0.8 \%$ of the total number of beats/ $24 \mathrm{~h}$. The majority of atrial FS episodes were followed by properly functioning AV safety delays. In these patients atrial sensing was reprogrammed to $0.1 \mathrm{mV}$ with IEGM recording to prevent oversensing. In 2 patients the lowest sensitivity without oversensing
Table I. Clinical characteristics of patients who participated in the study - studied population $(n=100)$

\begin{tabular}{|lc|}
\hline Parameter & Value \\
\hline Males, $n$ (\%) & $58(58)$ \\
\hline Age [years] & $\begin{array}{c}52-78 \\
\text { (mean: } 67.5 \pm 7.3)\end{array}$ \\
\hline Left ventricle ejection fraction & $\begin{array}{c}42-74 \% \\
\text { (mean: } 56 \pm 12 \%)\end{array}$ \\
\hline \begin{tabular}{l} 
Indication for pacemaker implantation [\%] \\
\hline Sick sinus syndrome
\end{tabular} & 52 \\
\hline Atrioventricular block & 43 \\
\hline Other & 5 \\
\hline
\end{tabular}

Table II. Electrical parameters of DDD pacemakers in one study group. The table shows the mean parameter values assessed 1 day after the device implantation

\begin{tabular}{|lc|}
\hline Parameter & Value \\
\hline Atrial pacing threshold [V] & $0.5 \pm 0.4$ \\
\hline Ventricular pacing threshold [V] & $0.4 \pm 0.3$ \\
\hline P wave amplitude [mV] & $2.8 \pm 0.9$ \\
\hline R wave amplitude [mV] & $12.4 \pm 8.2$ \\
\hline Atrial lead impedance [Ohm] & $643 \pm 204$ \\
\hline Ventricular lead impedance [Ohm] & $680 \pm 328$ \\
\hline
\end{tabular}

Table III. Number of pts with pacemaker dysfunction episodes found via ambulatory Holter monitoring one day after the implantation - studied population $(n=100)$

\begin{tabular}{|lc|}
\hline Pacemaker disturbances & Value \\
\hline $\begin{array}{l}\text { Failure to sense - atrial oversensing } \\
(\text { FSO A), } n(\%)\end{array}$ & $1(1)$ \\
\hline $\begin{array}{l}\text { Failure to sense - ventricular oversensing } \\
(\text { FSO V), } n \text { (\%) }\end{array}$ & $9(9)$ \\
\hline $\begin{array}{l}\text { Failure to sense - atrial undersensing } \\
\text { (FSU A), } n(\%)\end{array}$ & $12(12)$ \\
\hline $\begin{array}{l}\text { Failure to sense - ventricular undersensing } \\
(\text { FSU V), } n \text { (\%) }\end{array}$ & 0 \\
\hline Atrial failure to pace (FP A), $n$ (\%) & $1(1)$ \\
\hline \begin{tabular}{l} 
Ventricular failure to pace (FP V), $n$ (\%) \\
\hline Pacemaker mediated tachycardia (PMT), $n(\%)$
\end{tabular} & $4(4)$ \\
\hline All pacemaker disturbances, $n(\%)$ & $23(23)^{*}$ \\
\hline
\end{tabular}

*In 2 patients FSU A and PMT episodes occurred together

was $0.3 \mathrm{mV}$. After this procedure, the next HM was performed. A significant decrease in FSU episodes was found. In 3 patients with paroxysmal atrial fibrillation incidents, FSU episodes during the arrhythmia were not evaluated.

As to ventricular failure to sense, $T$ wave oversensing was the most common ventricular channel disorder. The number of ventricular FSO episodes ranged from 1 to 1000 (mean 146/median 16). These 
episodes occurred sporadically during daytime as well as nighttime, and were accompanied by pauses of $1100 \mathrm{~ms}$ up to $1600 \mathrm{~ms}$ and/or temporary bradycardia. Neither the pauses nor bradycardia provoked any clinical symptoms. The increase of the ventricular refractory period from $250 \mathrm{~ms}$ to 300 ms in PM eliminated T wave oversensing in all patients, confirmed with 24-hour HM. Summarized results of number of pts with PM disturbances, total number, the mean and the median value of failure to sense episodes: atrial undersensing and ventricular oversensing in 24-hour HM before and after PM parameters correction are shown in Table IV.

No ventricular pacing disturbances were found (Table III). Retrograde conduction occurred in 24 patients (24\%), ranging from $160 \mathrm{~ms}$ to $220 \mathrm{~ms}$. Pacemaker mediated tachycardia episodes were reported in 4 patients ( 3 patients with atrial undersensing and 1 patient with failure of atrial capture) with the longest episode being $3.4 \mathrm{~s}$ at a heart rate of $120 \mathrm{bpm}$. No cross-sensing episodes were found. The aforementioned sensing and pacing disturbances did not lead to any clinically significant pauses; no hemodynamic consequences were observed.

\section{Discussion}

Ambulatory Holter monitoring is a valuable complementary method for diagnosing pacing and sensing abnormalities in pacemaker patients [6, 9-13]. Twenty-four-hour ECG monitoring allows one to evaluate sensing and pacing, to detect asymptomatic stimulation disturbances as well as to determine arrhythmia events all day long and in different life situations [14-17]. The value of Holter electrocardiography in patients with pacemakers was first suggested by Ivengar et al. in 1971 by documenting pacemaker failure [6]. The report of Mymin et al. from 1973 describing symptomatic myo- potential interference in unipolar ventricular demand VVI pacemakers suggested that such disturbances could also be detected by Holter electrocardiography [7]. In 1974, Bleifer reported pacemaker malfunction (presumably in VVI devices) by Holter recordings in $18 \%$ of patients thought to have normal pacemaker function at the time of routine follow-up, and recommended Holter recordings for all patients with newly implanted pacemakers before leaving the hospital [17]. Our studies confirmed that patients with VVI pacemakers and unipolar leads should undergo HM [21]. On the other hand, in patients with bipolar leads the results were completely different. Only $1.5 \%$ of patients with bipolar leads experienced sensing disturbances (1 patient myopotential inhibition, another one an oversensing episode) compared to $21 \%$ of patients with unipolar leads $[18,19]$. That is why HM is not recommended in patients with VVI pacemakers and bipolar leads.

The new indications for PM implantation require more and more complex devices, equipped with sophisticated algorithms and numerous automatic functions. The increasing complexity of PMs goes hand in hand with a more careful follow-up procedure. However, the data about the value of ambulatory HM in patients with dual-chamber PMs, especially early after the implantation, is limited. ACC/AHA guidelines do not recommend $\mathrm{HM}$ as the routine examination in asymptomatic patients after PM implantation [8].

Our study of HM performed on the day after uncomplicated pacemaker implantation revealed PM dysfunction episodes in 23 patients (23\%). Although the electrical parameters (collected immediately before activation of Holter monitoring) from standard pacemaker telemetry were satisfactory, no lead displacement was found (checked via radiography), pacing and sensing function in standard

Table IV. Number of patiens with PM disturbances, total number, the mean and the median value of failure to sense episodes: atrial undersensing in 12 patients and ventricular oversensing in 9 patients with DDD PMs observed during ambulatory 24-hour ECG Holter monitoring before and after PM parameters correction

\begin{tabular}{|c|c|c|c|c|c|c|}
\hline & $\begin{array}{c}\text { Total number } \\
\text { of patients } \\
\text { before PM } \\
\text { parameters } \\
\text { correction }\end{array}$ & $\begin{array}{l}\text { Total number } \\
\text { of patients } \\
\text { after PM } \\
\text { parameters } \\
\text { correction }\end{array}$ & Value of $p$ & $\begin{array}{l}\text { Total number } \\
\text { and mean } \\
\text { episodes } \\
\text { before PM } \\
\text { parameters } \\
\text { correction }\end{array}$ & $\begin{array}{l}\text { Total number } \\
\text { and mean } \\
\text { episodes } \\
\text { after PM } \\
\text { correction }\end{array}$ & Value of $p$ \\
\hline FSU A & 12 (100\%) & $2(17 \%)$ & $<0.005$ & $\begin{array}{c}963 \\
\text { Mean }=80 \\
\text { Median }=16 \\
(\text { Min-max }=5-700)\end{array}$ & $\begin{array}{c}70 \\
\text { Mean }=6 \\
\text { Median }=0 \\
(\text { Min-max }=0-58)\end{array}$ & $<0.05$ \\
\hline FSO V & 9 (100\%) & 0 & $<0.00005$ & $\begin{array}{c}1316 \\
\text { Mean }=146 \\
\text { Median = 16 } \\
(\text { Min-max = 1-1000) }\end{array}$ & $\begin{array}{c}0 \\
\text { Mean }=0 \\
\text { Median }=0 \\
(\text { Min-max }=0-0)\end{array}$ & $<0.01$ \\
\hline
\end{tabular}

FSU A - failure to sense - atrial undersensing, FSO V failure to sense - ventricular oversensing, PM - pacemaker 
ECG were correct, and the percentage of disturbances recorded via HM was relatively high. According to the literature, atrial undersensing episodes are the most common disturbances observed during HM in patients with DDD pacemakers [20]. This observation is supported by our study as well. The mean number of atrial undersensing episodes observed in 12 patients was relatively low (79 episodes), representing only $0.8 \%$ of total heart beats/24 h. Only 1 patient displayed 700 undersensing episodes, the others less than 100 (even the patient with the highest number of undersensing episodes reported no clinical symptoms). The only parameter which is responsible for this kind of disturbance is atrial sensitivity. In all these patients, after decreasing the value of PM sensitivity, the percentage of FSU episodes was significantly lower. However, according to other studies, it is important to note the risk of atrial oversensing, if sensitivity is less than $0.5 \mathrm{mV}$ [21-24]. Moreover, in the case of such a low value, IEGM should always be checked because of the risk of atrial QRS and far-field oversensing [25-27]. The majority of the atrial undersensing episodes were connected with properly functioning AV safety pacing - $100 \mathrm{~ms}$. It is important to note that a ventricular spike behind the $\mathrm{R}$ wave does not mean undersensing in the ventricular channel. The spike refers to the $R$ wave, which occurred during the blanking period and should not be sensed.

On the other hand, the high number of ventricular oversensing episodes compared to other studies $[28,29]$ is confusing. T wave oversensing was the most frequently observed ventricular channel disturbance. The mean RR pause lasted for 1360 ms. Although IEGM did not reveal T wave oversensing during follow-up in any patient, HM was able to recognize these incidents. T wave oversensing, which in some patients can lead to presyncope or syncope, should be considered when changing PM parameters. It seems that a standard ventricular refractory period (VRP) of $250 \mathrm{~ms}$ is a bit too short. This T wave sensing could easily be avoided by setting the ventricular refractory period between $250 \mathrm{~ms}$ to $300 \mathrm{~ms}$ or more. The second HM, performed after changing VRP from 250 ms to 300 ms, did not reveal any FSO episode. We might consider lengthening VRP up to 300 ms directly after the implantation. It was confirmed in our previous studies with VVI PM with bipolar leads (VRP $=300 \mathrm{~ms})$ that only $1.5 \%$ FSO occurred $[18,19]$. The second solution is to decrease sensitivity in the ventricular channel. Medical literature also states that QRS oversensing may lead to overestimation of mode switching in pacemaker memory data [30, 31].

Although the longest retrograde conduction (220 ms) with the following preset parameters (AV delay $180 \mathrm{~ms}$, ARP $450 \mathrm{~ms}$ ) should terminate PMT, these incidents were found in 24 patients. We cannot exclude the possibility of prolonged VA retrograde conduction during daily activity.

Our study showed that HM may reveal pacemaker disturbances in almost $25 \%$ of asymptomatic patients with proper PM parameters after implantation. Undersensing and oversensing episodes, being the most frequent PM dysfunction, did not lead to clinically significant pauses or bradycardia episodes. All these disorders were eliminated by PM reprogramming. In order to check if reprogramming yielded the desired results, 24 HM was performed.

In conclusion, the study showed that, although modern dual-chamber PMs are perfect devices for pacing, the risk of oversensing and undersensing episodes remains. Twenty-four-hour ambulatory Holter monitoring performed during the early postimplantation period may detect pacing and sensing dysfunction episodes even in patients who display proper pacemaker parameters on standard pacemaker telemetry. These PM malfunctions, although asymptomatic, may be corrected via PM programmers in every patient. Pauses and bradycardia episodes observed in our patients during the early post-implantation period did not provoke any hemodynamic consequences; however, we cannot exclude the occurrence of future symptomatic episodes. Therefore, HM allows the programming of more appropriate PM parameters in some patients.

\section{References}

1. Montanez A, Hennekens CH, Zebede J, Lamas G. Pacemaker mode selection: the evidence form randomized trials. Pacing Clin Electrophysiol 2003; 26: 1270-82.

2. Furman S, Hayes DL, Homes DR. Telemetry. A practice of cardiac pacing. Futura Publishing, Mt Kisco 1993; 633-41.

3. Newman D, Dorian P, Downar E. Use of telemetry function in the assessment of implanted antitachycardia device efficacy. Am J Cardiol 1992; 70: 616-21.

4. Lascault G, Frank R, Himbert C. Diagnosis of ventricular tachycardia using a pacemaker Holter function. Pacing Clin Electrophysiol 1994; 17: 1316-9.

5. Levine PA, Sanders R, Rankowitz HT. Pacemaker diagnostics: measured data, event marker, electrogram, and event counter telemetry. In: Clinical cardiac pacing. Ellenbogen KA, Kay GN (eds). WB Saunders Co, Philadelphia, PA 1995; 639-55.

6. Ivengar R, Castellanos A, Spence M. Continuous monitoring of ambulatory patients with coronary disease. Prog Cardiovasc 1971; 13: 392-404.

7. Mymin D, Cuddy TE, Sinha SD, Winter DA. Inhibition of demand pacemakers by skeletal muscle potentials. JAMA 1973; 223: 527-99.

8. Kadish $A H$, Buxton $A E$, Kennedy $H L$, et al.; ACC/AHA clinical competence statement on electrocardiography and ambulatory electrocardiography: A report of the ACC/AHA/ACP-ASIM task force on clinical competence (ACC/AHA Committee to develop a clinical competence statement on electrocardiography and ambulatory 
electrocardiography) endorsed by the International Society for Holter and noninvasive electrocardiology. American College of Cardiology/American Heart Association/ American College of Physicians-American Society of Internal Medicine Task Force; International Society for Holter and Noninvasive Electrocardiology. Circulation 2001; 18: 3169-78.

9. Hayes DL, Lloyd MA, Friedman AP. Cardiac pacing and difibrillation. A clinical approach. Futura Publishing Co, Inc. Armonk NY Co, 2000; 1: 15-6.

10. Oka Y, Ito T, Sada T, et al. Ambulatory electrocardiograms obtained by Holter monitoring system in patients with permanent demand pacemakers. Jpn Heart J 1985; 26: 23-32.

11. Kaul UA, Balachander J, Khalilullah M. Ambulatory monitoring in patients with implanted pacemakers. Indian Heart J 1984; 36: 23-6.

12. Pavlovic SU, Kocovic D, Djordievic M, Belkic K, Kaostic D, Velimirovic D. The etiology of syncope in pacemaker patients. Pacing Clin Electrophysiol 1991; 14: 2086-91.

13. Wranicz JK, Strzondala M, Zrobek J, Ruta J, Krekora J, Maciejewski M. 24-hours ECG Holter monitoring - detection of asymptomatic stimulation disturbances in patients with artificial pacemakers. Med Sci 1999; 5: 262-4

14. Watson WS. Myopotential sensing in cardiac pacemakers. In: Modern cardiac pacing. Barold SS (ed.). Futura Publishing, Mt. Kisco, NY 1985; 813-37.

15. Gaita F, Asteggiano R, Bocchiardo M, et al. Holter monitoring and provocative maneuvers in assessment of unipolar demand pacemaker myopotential inhibition. Am Heart J 1984; 107: 925-8.

16. Fetter J, Bobeldyk GL, Engman FJ. The clinical incidence and significance of myopotential sensing with unipolar pacemakers. Pacing Clin Electrophysiol 1984; 7: 871-81.

17. Bleifer SB. Diagnostic of occult arrhythmias by Holter Electrocardiography. Prog Cardiovasc Dis 1974; 16: 569-99.

18. Wranicz JK, Chudzik M, Cygankiewicz I. The value of 24 hours ECG Holter monitoring in asymptomatic patients with VVI pacemaker. Fol Cardiol 2001; 8: 31-4.

19. Wranicz JK, Chudzik M, Cygankiewicz I. From unipolar to bipolar leads - fewer problems more advantages? Prog Biomed Res 2003; 8: 1-6.

20. Wiegand U, Bonnemeier $\mathrm{H}$, Bode $\mathrm{F}$, et al. Continuous holter telemetry of atrial electrograms and marker annotations using a common holter recording system: impact on Holter electrocardiogram interpretation in patients with dual chamber pacemakers. Pacing Clin Electrophysiol 2002; 25: 1724-30.

21. Brandt J, Fahraeus T, Schuller H. Far field QRS complex sensing via the atrial pacemaker lead. Mechanism and consequences, differential diagnosis and countermeasures in AAI and VDD/DDD pacing. Pacing Clin Electrophysiol 1988; 11: 1432-8.

22. Brandt J, Worzewski W. Far field QRS complex sensing: prevalence and timing with bipolar atrial leads. Pacing Clin Electrophysiol 2000; 23: 315-20.

23. Frohlig G, Helwani Z, Kusch O, Berge M, Schieffer $H$. Bipolar ventricular far field signals in the atrium. Pacing Clin Electrophysiol 1999; 22: 1604-13.

24. Brouwer J, Nagelkerte D, den Heijer P. Analysis of atria sensed far field ventricular signals: a reassessment. Pacing Clin Electrophysiol 1997; 20: 916-20.

25. Bordacher P, Cazeau S, Graindorg J, Ritter P. Impact and prevention of far-field sensing in fallback mode switches. Pacing Clin Electrophysiol 2003; 26: 206-9.
26. Bonnet IL, Brusseau E, Limousin M. Mode switch despite undersensing of atrial fibrillation in DDD pacing. Pacing Clin Electrophysiol 1996; 19: 1724-8.

27. Fitts SM, Hill MRS, Mehra R, Gillis AM; the PA Clinical Trial Investigator. High rate atrial tachyarrhythmia detection in implantable pulse generator. Pacing Clin Electrophysiol 2000; 23: 1080-6.

28. Israel CW. Analysis of mode switching algorithms in dual chamber pacemaker. Pacing Clin Electrophysiol 2002; 25: 380-93.

29. Maury P, Schlaepfer M, Arbane G, Girod G, Kappenberger $L$. Incessant atrioventricular dissociation due to far field QRS oversensing and recurrent mode switch in a dual chamber pacemaker. Europace 2002; 4: 149-53.

30. Israel CW. Analysis of mode switching algorithms in dual chamber pacemaker. Pacing Clin Electrophysiol 2002; 25: 380-93.

31. Maury P, Schlaepfer M, Arbane G, Girod G, Kappenberger $L$. Incessant atrioventricular dissociation due to far fileld QRS oversensing and recurrent mode switch in a dual chamber pacemaker. Europace 2002; 4: 149-53. 